\title{
A PUBLICAÇÃO PERIÓDICA ILUSTRADA BRASILEIRA NO SÉCULO XIX
}

Letícia Pedruzzi Fonseca

Universidade Federal do Espírito Santo

leticia.fonseca@ufes.br

Resumo: O presente artigo aborda a modernidade e o papel das revistas ilustradas como mediadoras do confronto entre a população e as novidades da convivência urbana e dos inúmeros novos produtos oitocentistas. Apresenta de forma abrangente como se iniciou e consolidou a publicação de revistas ilustradas no Brasil, apresentando os principais títulos, seus produtores e inovações. São levantadas informações sobre os projetos gráficos e a tecnologia utilizada na produção das revistas, traçando um panorama da publicação periódica ilustrada na segunda metade do século XIX. Por fim, são apresentadas as principais características gráficas das revistas ilustradas oitocentistas, de forma a destacar peculiaridades e semelhanças.

Palavras-chave: modernidade; revistas ilustradas brasileiras, século XIX, produção gráfica, história do design.

\begin{abstract}
This paper discusses the modernity and the role of illustrated magazines as mediators of the confrontation between the people and the novelties of urban life and the numerous news nineteenth century products. It presents in a general way how began and consolidation of illustrated maganizes publishing in Brasil, presenting the main titles, its producers and inovations. Also information detailed about graphic projects and the technology used on the maganizes production, tracing a overview of the illustrated periodical publication on the second half of century 19th. Finally, it presents the main graphic characteristics of nineteenth illustrated magazines, highlighting singularities and similarities.
\end{abstract}

Keywords: Modernity; Brazilian illustrated magazines, nineteenth century, graphic production, design history. 


\section{A MODERNIDADE E AS REVISTAS ILUSTRADAS}

$\mathrm{Na}$ década de 1860, quando a população urbana das grandes metrópoles europeias, como Londres e Paris, vivenciava a experiência de compartilhar com estranhos os novos meios de transporte, o grande fluxo de informações e imagens, o anonimato no meio da multidão e as estratégias de sociabilidade decorrentes dessas circunstâncias, o crítico francês Charles Baudelaire cunhou o termo "modernidade" (Cardoso, 2008, p. 46-47).

Baudelaire criticou as mudanças no ritmo de vida da população, o que chamou de vida moderna, e as mudanças na arte que ocorreram no âmbito da representação e na postura do artista. Surge nesse cenário o personagem do flâneur, que se distancia do pintor de coisas eternas e assume a representação da circunstância imediata e fugaz. O texto de Baudelaire elege como pioneiros dessa modalidade os célebres caricaturistas franceses Daumier e Gavarni (Baudelaire, 2010, p. 18-21).

No ensaio publicado no jornal francês Le Fígaro, em 1863, intitulado de 0 Pintor da Vida Moderna, Baudelaire discutiu o papel da arte na representação da modernidade latente, utilizando-se da produção do francês Constantin Guys, a quem chamou de Sr. G. ao longo do ensaio, supondo não identificá-lo. Tratava-se de um artista que não gostava de se rotular como tal, e colaborava no primeiro semanário ilustrado do mundo, o Illustrated London News, que lhe atribuiu o título de "artistarepórter". Baudelaire concedeu várias informações sobre o artista gráfico: era cosmopolita, habituado a viajar, um homem do mundo, que compreendia o mundo, tendo a curiosidade como ponto de partida de seu gênio (Baudelaire, 2010, p. 22-24).

Agora, no momento em que os outros dormem, esse homem está curvado sobre a mesa, lançando sobre uma folha de papel o mesmo olhar que há pouco fixava sobre as coisas, esgrimindo com seu lápis, sua caneta, seu pincel, respingando no teto a água do copo, limpando a pena na camisa, apressado, violento, ativo, como se temesse que as imagens the escapassem, brigando sozinho, esbarrando em si mesmo. Assim, as cenas apareciam sobre o papel, naturais e belas, segundo Baudelaire, reflexo da alma do autor e sua vida em estado de exaltação. Essa busca do artista por representar além do prazer fugaz da circunstância, de extrair o eterno do transitório, foi chamada de modernidade. "A modernidade é o transitório, o fugidio, o contingente, a metade da arte, cuja outra metade é o eterno e o imutável" (Baudelaire, 2010, p. 32-35).

Essa nova forma de representação está ligada à tradução de impressões próprias do artista, que desenha de memória e não segundo um modelo: a inscrição da imagem no cérebro do flâneur determina a obra, e não a natureza. O "artista-repórter" age como um tradutor da realidade, faz proposições de análise da sociedade, e sua produção é o resultado de instantes apreendidos, interpretados e recompostos, ao contrário da fotografia, que transmite apenas um instante mecanicamente imobilizado e quimicamente fixado (Dufilho apud Baudelaire, 2010, p. 115).

Além das grandes e irreversíveis transformações no cotidiano das pessoas, um dos fatores que distinguiu o século XIX como momento inicial da modernidade baudelairiana foi a evolução dos meios impressos de comunicação (Cardoso, 2008, p. 46-48). Com os avanços na tecnologia gráfica, a popularização dos impressos, inclusive ilustrados, e o crescimento do público leitor, com poder aquisitivo e interesse em consumir periódicos, a imprensa se desenvolveu largamente. Os periódicos ilustrados 
foram importantes na assimilação dos impactos e mudanças que o processo modernizador causou nos centros urbanos.

As revistas ilustradas utilizavam uma linguagem acessível e desempenhavam o papel de auxiliar na compreensão da vida contemporânea, o que facilitou a emergência do "artista-repórter" baudelairiano, ou seja, o caricaturista, e sua nova expressão artística. Com representações bem-humoradas e satíricas das impactantes transformações que estavam ocorrendo numa velocidade espantosa, as publicações amenizavam a aflição e desconforto provocados pelas inéditas situações e produtos com quais a população passou a ter contato a partir dos desenvolvimentos do século XIX. O caricaturista ganhou destaque nas publicações, já que a imagem representou um dos principais produtos da modernidade. $O$ impacto da revolução na comunicação visual foi considerado pelo engenheiro britânico Robert Scott Burn "mais poderosa do que a que havia sido efetuada pela prensa para impressão de palavras" (Burn apud Cardoso, 2005, p. 160-161).

A caricatura materializava as novidades, a mudança de paradigmas da sociedade com leveza e humor. Foi a manifestação artística que dominou e marcou o período pelo poder de síntese, por acompanhar o ritmo cada vez mais veloz dos acontecimentos e pelas novas possibilidades gráficas que permitiu sua publicação corriqueira nas revistas ilustradas. De acordo com Velloso, a ilustração tornou-se essencial para a comunicação que se pretendia moderna (Velloso, 1996, p. 60).

A pesquisadora Laura Nery contribui para a compreensão da passagem da caricatura artística para uma poderosa forma de representação política do século XIX. Além do papel de mediadora da assimilação da modernidade, a caricatura foi muito utilizada nos embates políticos, porém merece ser destacada a sua representatividade como uma manifestação artística acima de tudo, a arte na modernidade. Segundo Baudelaire, ela constituiria a própria estética da modernidade (Nery, 2006, p. 11-12).

A justaposição, a hipérbole, o exagero, a síntese formal, a imaginação somada à observação da realidade, a junção de motivos "altos e baixos", a ênfase no efeito sobre o observador - o essencialmente caricatural ou cômico - criticamente incorporados às artes plásticas e literárias, deixam de ser recursos representacionais alternativos, e tornam-se o próprio paradigma do que ele define por moderno (Nery, 2006, p. 15).

A publicação assídua das caricaturas enriqueceu as revistas ilustradas, que se transformaram em objetos atraentes e acessíveis até mesmo aos menos afeitos à leitura, que decifravam as mensagens através das imagens publicadas (Martins, 2008, p. 40). Ao longo do século XIX, a revista tornou-se moda e, sobretudo, ditou moda. Sem dúvida essa tendência tinha uma explicação, referendada na Europa pela conjuntura propícia, definida pelo avanço técnico das gráficas, aumento da população leitora e alto custo do livro; favoreceu-a definitivamente, o mérito de condensar, numa só publicação, uma gama diferenciada de informações, sinalizadora de tantas inovações propostas pelos novos tempos (Martins, 2008, p. 40).

Nesse contexto, o ilustrador tornou-se o profissional imprescindível das revistas, era o flâneur a serviço da necessidade de materializar mensagens e interpretações do cotidiano com rapidez. Esse profissional garantia o sucesso das vendas, qualificando as publicações com seu traço, e, por vezes, em atuação mais importante que o redator (Martins, 2008, p. 184).

Com a acirrada concorrência entre as revistas ilustradas, o papel do artista gráfico adquiriu valor redobrado, pois, com a mecanização do parque gráfico, o critério 
que distinguia a qualidade dos impressos deixou de ser a habilidade de execução e passou a ser a originalidade do projeto e das ilustrações. Segundo Cardoso, na segunda metade do século XIX surgiu uma nova preocupação com a qualidade dos projetos, e alguns poucos desenhistas conseguiram se notabilizar por meio do seu trabalho editorial, como, por exemplo, os caricaturistas Daumier e Gavarni na França (Cardoso, 2008, p. 48-49).

\section{O INÍCIO DA PUBLICAÇÃO DE REVISTAS ILUSTRADAS BRASILEIRAS}

Durante a segunda metade do século XIX a produção de revistas ilustradas predominou na imprensa brasileira com conteúdo satírico-humorístico e ilustrações impressas em litografia. De 1865 a 1895, circularam no Rio de Janeiro mais de 60 revistas ilustradas (Teixeira, 2001, p. 3). Henrique Fleiuss implantou um modelo na publicação da Semana llustrada, que foi publicada entre 1860 e 1876. Depois surgiram diversos títulos importantes como A Vida Fluminense (1868-1875), O Mosquito (18691877), O Mequetrefe (1875-1893) e a Revista Ilustrada (1876-1898), apenas para citar os que tiveram vida mais duradoura. Para Cardoso, o gênio dos desenhistas como Fleiuss, Agostini e Bordalo, todos estrangeiros, foi determinante para gerar uma cultura de consumo de imagens no Brasil (Cardoso, 2009, p. 122).

Nesse ambiente de imprensa do Segundo Reinado, destacaram-se as revistas ilustradas, que, ao lado dos jornais diários, foram ganhando, ao longo dos anos, lugar de destaque como veículo de ideias e espaço de expressão da imaginação social. [...] Como os jornais raramente e de modo muito episódico fizeram uso da imagem, as revistas ilustradas definiram um gênero muito particular de periódicos. Sua novidade mais importante foi afirmar o papel da imagem na construção da narrativa jornalística (Knauss, 2011, p. 11).

No curso do desenvolvimento da imprensa brasileira, tem-se uma longa lista de revistas ilustradas que marcaram o período, mesmo com a efemeridade da maioria. Pode-se perceber que a valorização e o consumo de imagens consolidaram uma cultura visual sólida e própria, distinta das diversas matrizes europeias e americanas que lhes davam origem. Existia, sim, a influência e a marcada estrutura de divisão de texto e imagem, que foi característica das revistas nacionais e estrangeiras, delimitadas pela incompatibilidade no princípio de impressão dos diferentes tipos de conteúdo. Apesar do talento e inventividade dos ilustradores que comandavam a publicação dos semanários, constatou-se a consolidação de um padrão gráfico e visual mais ou menos estável, com o uso recorrente da litografia como técnica e linguagem no período (Cardoso, 2009, p. 78-79).

Assim, pode-se afirmar que a grande maioria da produção de imagens para as revistas ilustradas brasileiras no século XIX se deu a partir da técnica litográfica, que chegou ao país sem grande atraso, como foi o caso da própria imprensa de tipos móveis, que sofria censura de Portugal e só foi implantada com a vinda da Família Real para o Brasil, em 1808, e logo se desenvolveu. Tem-se a notável exceção de revistas que utilizaram outras tecnologias para ilustrar suas páginas, como Museu Universal (figura 1), Brasil llustrado (figura 2) e algumas experiências nas publicações de Henrique Fleiuss, por conta da produção xilográfica de seu Instituto Artístico. 

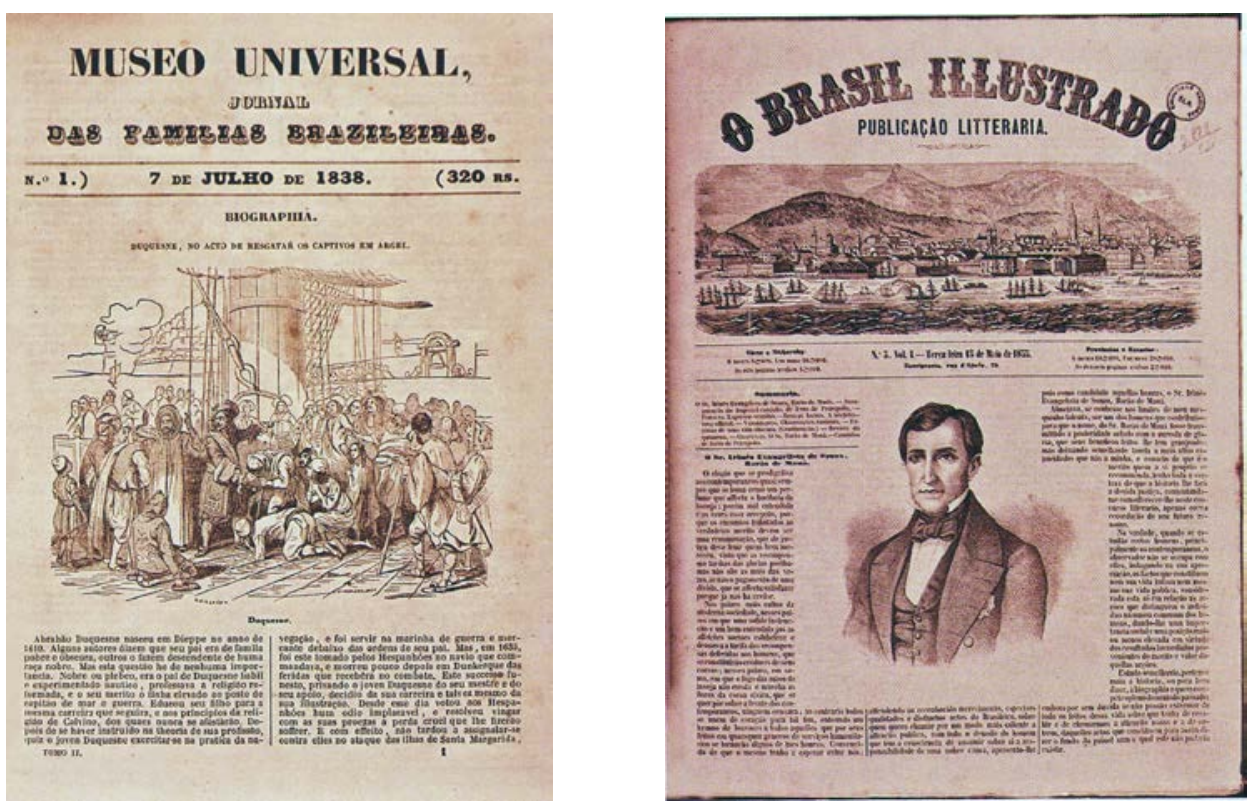

Figura 01. Museu Universal, 1838.

Fonte: Museu Universal, n. 1, 07/07/1838, p. 1. Acervo da Fundação Biblioteca Nacional - Brasil.

Figura 02. Brasil Ilustrado, 1855.

Fonte: Brasil Ilustrado, n. 3, 15/05/1855, capa. Acervo da Fundação Biblioteca Nacional - Brasil.

A revista Museu Universal: Jornal das famílias brasileiras, publicada entre 1838 e 1844, era composta majoritariamente por textos e ilustrações criados no exterior e adaptados para o público brasileiro por J. Villeneuve e Cia., que, na época, produzia também o Jornal do Comércio. Cardoso discute o fato de a revista Museu Universal ter sido ignorada por estudiosos da história da imprensa brasileira, em detrimento do crédito dado à revista Lanterna Mágica, produzida por Araújo Porto-Alegre e que iniciou a publicação de caricaturas apenas em 1844. Tal distorção pode ter acontecido pelo fato de as imagens serem importadas, porém a referida revista "surgiu na sociedade brasileira na tentativa de suprir uma demanda percebida por informação visual". Fato é que Museu Universal circulou por seis anos, tempo considerável se comparado ao período de circulação da maioria dos periódicos do século XIX, e veiculou em média 200 ilustrações por ano. Foi pioneira junto à revista ilustrada L'Echo Français, editada também por Villeneuve em 1838 (Cardoso in Knauss, 2011, p. 20).

A qualidade e a variedade dos clichês produzidos por boas oficinas europeias devem ter revolucionado o olhar de toda uma geração de pequenos leitores, que despertava para o grande mundo descortinado para as famílias brasileiras por esse periódico (Cardoso in Knauss, 2011, p. 20).

Embora os atores envolvidos na produção e impressão de periódicos no Brasil oitocentista fossem, em grande parte, estrangeiros, é preciso considerar que o local onde o clichê foi desenhado ou impresso e a procedência do ilustrador não alteravam o impacto sobre o cenário editorial em que uma imagem era consumida. Essa reflexão é muito importante para a história da imprensa brasileira, para que se leve em consideração a produção e a disseminação de publicações, que foram muito importantes para o desenvolvimento da imprensa, independente da nacionalidade dos atores, tecnologia ou produção (Cardoso in Knauss, 2011, p. 22). 
A partir da segunda metade do século XIX, a litografia prevaleceu como técnica de produção de imagens no Brasil, pois, com a liberdade conferida ao artista no desenho direto sobre a superfície plana, texto e imagem podiam se integrar no desenho e diferentes desenhos de letras podiam ser produzidos a cada nova impressão. Essas composições de letras desenhadas na pedra podiam ser dispostas em qualquer direção, dependendo somente da habilidade e criatividade do ilustrador. Essa característica foi muito enriquecedora numa época em que a apresentação de texto e imagem era restringida pelas limitações do sistema tipográfico de impressão, que funcionava com o entintamento da superfície em alto relevo. A matriz xilográfica, por exemplo, que possui o mesmo princípio de impressão da tipografia e pode ser articulada na galé com o texto, tinha a produção dispendiosa e demorada se comparada à matriz litográfica.

A litografia foi largamente utilizada na publicação de imagens no Brasil e os ilustradores mantiveram um uso similar da técnica e de construção de imagens, apresentando uma estética pautada na apresentação de traços e meios tons permitidos pelo uso do crayon sobre a pedra porosa.

Diferentemente da complexa cadeia produtiva e do alto grau de especialização exigido pela xilogravura de topo - técnica preferida das melhores revistas ilustradas da Europa e Estados Unidos -, a litografia permitia a um único indivíduo habilidoso assumir, de modo centralizado, a confecção das ilustrações. A monotonia resultante era compensada por ganhos de autonomia editorial e custos baixos (Cardoso in Knauss, 2011, p. 28).

As revistas ilustradas ampliaram seu público com o passar das décadas por intermediar o jornal e o livro, que ainda era um objeto sacralizado, custoso e ao alcance de poucos. A revista também informava como o jornal, era um noticiário ligeiro e seriado, porém de forma mais leve, amparada pelo humor. Além disso, tinha um custo acessível, uma configuração leve, com poucas folhas e leitura entremeada por imagens (Martins, 2008, p. 40).

A revista, na sua modalidade específica de impresso ligeiro, beneficiou-se profundamente dessa circunstância literária, técnica e mercadológica; desde que submetida às suas regras. Permitiu o abuso da literatura a serviço da reportagem e, precedendo o jornal, resultou em veículo para experimentos da modernidade técnica. Com uma diferença do periodismo pregresso, pois proliferou em outras mãos: as de homens de mercado, que faziam da revista seu negócio (Martins, 2008, p. 142-144).

O desenvolvimento industrial e comercial, em diferentes âmbitos, também teve início no Brasil durante o período oitocentista e muito mais concentrado no Rio de Janeiro, capital do Império e, depois, da República. Identificou-se um crescimento da classe média urbana e a ampliação das atividades culturais ligadas à imprensa. Firmaram-se no Rio de Janeiro empresas como a Laemmert, em 1838, que passou a se fazer conhecida pela divulgação de sua folhinha-calendário a partir de 1839 , quando se tornou famosa, e, a partir de 1844, pela publicação do tradicional almanaque que ganhou prestígio e foi publicado até 1930 (Sodré, 1999, p. 206). Na década de 1860, a capital do Império começava a desfrutar de alguma vida social em espaços públicos e a imprensa ilustrada apareceu como uma nova alternativa de sociabilidade e entretenimento (Nery, 2011, p. 65)

O primeiro surto industrial brasileiro ocorreu nas décadas de 1870 e 1880 e limitou-se às fábricas de pequena escala. Apesar da pouca expressão econômica, os 
resultados desse surto foram importantes para a formação de um mercado consumidor interno e, ainda, por gerar demanda de projetos de design, que eram necessários para o desenvolvimento dos produtos e que contribuíram para a configuração da cultura material e visual da época (Cardoso, 2008, p. 38). O decênio de 1870 foi também o período de grande desenvolvimento da litografia brasileira, no qual funcionaram as melhores oficinas, segundo Ferreira. Nessa década foram contabilizados 248 diferentes impressores litográficos, o ápice da história da imprensa brasileira nos oitocentos. Os números apontam que em 1850 havia 115 impressores litográficos, número que aumentou para 197 em 1860, teve seu ápice na década de 1870, e começou a declinar para 178 no ano de 1880, e 128 em 1890 (Ferreira, 1994, p. 409-410).

Flora Sussekind afirma que o horizonte técnico serviu muitas vezes de interlocutor para a produção literária do período, especialmente a partir da década de 1880, e enumera uma gama de melhorias e inserções de novos aparatos técnicos de todos os tipos:

Passando pela ampliação da rede ferroviária (que em 1885 contava com 7.602 quilômetros de exploração, 2.268 em construção e 5.060 em projeto), pelo uso da iluminação elétrica nos teatros (que começou a ser feito, graças a um gerador a vapor, pelo Teatro Lucinda, no Rio de Janeiro, em 1887), pela adoção sistemática da tração elétrica nos bondes (o que fez a empresa Botanical Garden, no Rio, em 1894), pelo aparecimento dos primeiros balões aeroplanos, pelo número crescente de automóveis em circulação nas grandes cidades do país (de 6, em 1903, na Capital, para 35, em 1906), teria na difusão da fotografia, da telefonia, do cinematógrafo e do fonógrafo, na introdução de novas técnicas de registro sonoro e de impressão e reprodução de textos, desenhos e fotos, na expansão da prática do reclame, fatores decisivos para sua configuração (Sussekind, 1987, p. 29).

A inserção dessas novas possibilidades tecnológicas na sociedade foi transformando o ambiente e a vivência da população e pode ser relacionada ao que foi exposto anteriormente sobre o advento da modernidade nos grandes centros europeus, em vista de tantas transformações. No Brasil, as revistas também tiveram papel importante na assimilação da avalanche de novidades, dos embates políticos e alterações socioeconômicas que ocorreram, principalmente na segunda metade do século XIX. Contribuíram para a reconfiguração social do país a proibição do tráfico africano, em 1850, e o intenso comércio interno de escravos a partir de então; a Guerra do Paraguai, que durou de 1865 a 1870; as grandes secas do sertão nordestino nas décadas de 1870 e 1880; a Abolição da escravatura, em 1888; e, a proclamação da República em 1889 (Sevcenko, 1998, p. 55-56). A produção de Ângelo Agostini - por exemplo, na Revista Illustrada - pode ser considerada a mais influente de sua época, pois impactou fortemente a opinião pública durante as campanhas abolicionista e republicana.

Como a publicação de ilustrações era um indício de atualidade técnica, os desenhos e caricaturas eram quase sempre postos em evidência. E o caricaturista merecia lugar privilegiado nas publicações, pois sua produção não ocupava apenas a capa como lugar de destaque, mas uma grande proporção do periódico, tornando-se comum a caricatura preencher uma página inteira e até mesmo duas seguidas (Velloso, 1996, p. 59). 


\subsection{As principais características da apresentação gráfica das revistas ilustradas brasileiras oitocentistas}

Após a explanação panorâmica sobre o contexto e a produção das revistas ilustradas brasileiras no século XIX, pretende-se realizar algumas considerações sobre a apresentação gráfica desses impressos.

O aumento do número de títulos e da longevidade de algumas revistas ilustradas brasileiras, na segunda metade do século XIX, corrobora sua importância crescente na mediação e assimilação de questões sociais, políticas e econômicas por meio das imagens satíricas. A discussão, o debate e o destaque dado às questões que faziam parte do cotidiano da população pode ser o motivo desse tipo de publicação ter obtido sucesso e se multiplicado ao longo dos anos. Os embates políticos, que modificaram radicalmente a organização do país em um curto período de tempo, foram largamente satirizados nas páginas dos artistas do traço. 0 humor esteve presente na produção gráfica e intelectual da época, participando ativamente das discussões geradas, seja pelas críticas em relação aos novos produtos e costumes importados do Velho Mundo, seja em assuntos políticos.

O pioneirismo de Fleiuss (figura 3), a maestria de Agostini (figura 4) e a ousadia de Bordalo (figuras 5 e 6) fizeram da segunda metade do século XIX um período riquíssimo de produção iconográfica de toda sorte.
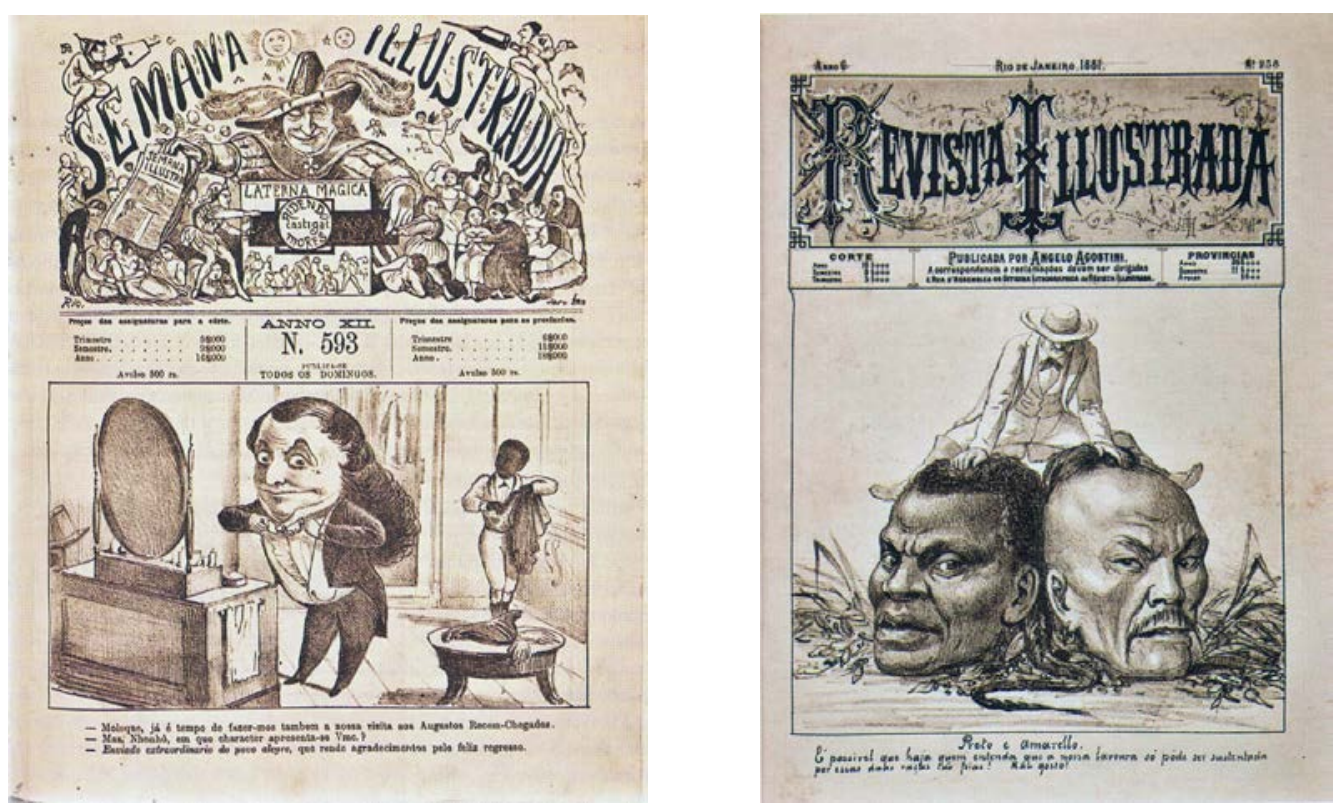

Figura 03. Dr. Semana e Moleque, personagens da Semana llustrada, 1872. Revista produzida por Henrique Fleiuss.

Fonte: A Semana llustrada, ano 12, n. 593, 21/04/1872, p.1. Acervo da Fundação Biblioteca Nacional Brasil.

Figura 04. Capa da Revista Ilustrada com representação realista de personagens, 1881. Revista produzida por Ângelo Agostini.

Fonte: Revista llustrada, ano VI, n. 258. Rio de Janeiro, 30/7/1881. P.1. Acervo da Fundação Biblioteca Nacional - Brasil.

A técnica litográfica predominou na produção de imagens, e seu uso similar por diversos artistas gráficos ditou a estética das ilustrações produzidas para as revistas ilustradas. A agilidade do processo litográfico, se relacionado à técnica da xilogravura 
de topo, por exemplo, que foi incentivada e valorizada por Fleiuss, fez com que ela predominasse nas publicações. Outra característica importante da litografia era a possibilidade do ilustrador desenhar diretamente sobre a pedra, eliminando a necessidade de contratação de um gravador para transpor a imagem para a matriz de impressão.
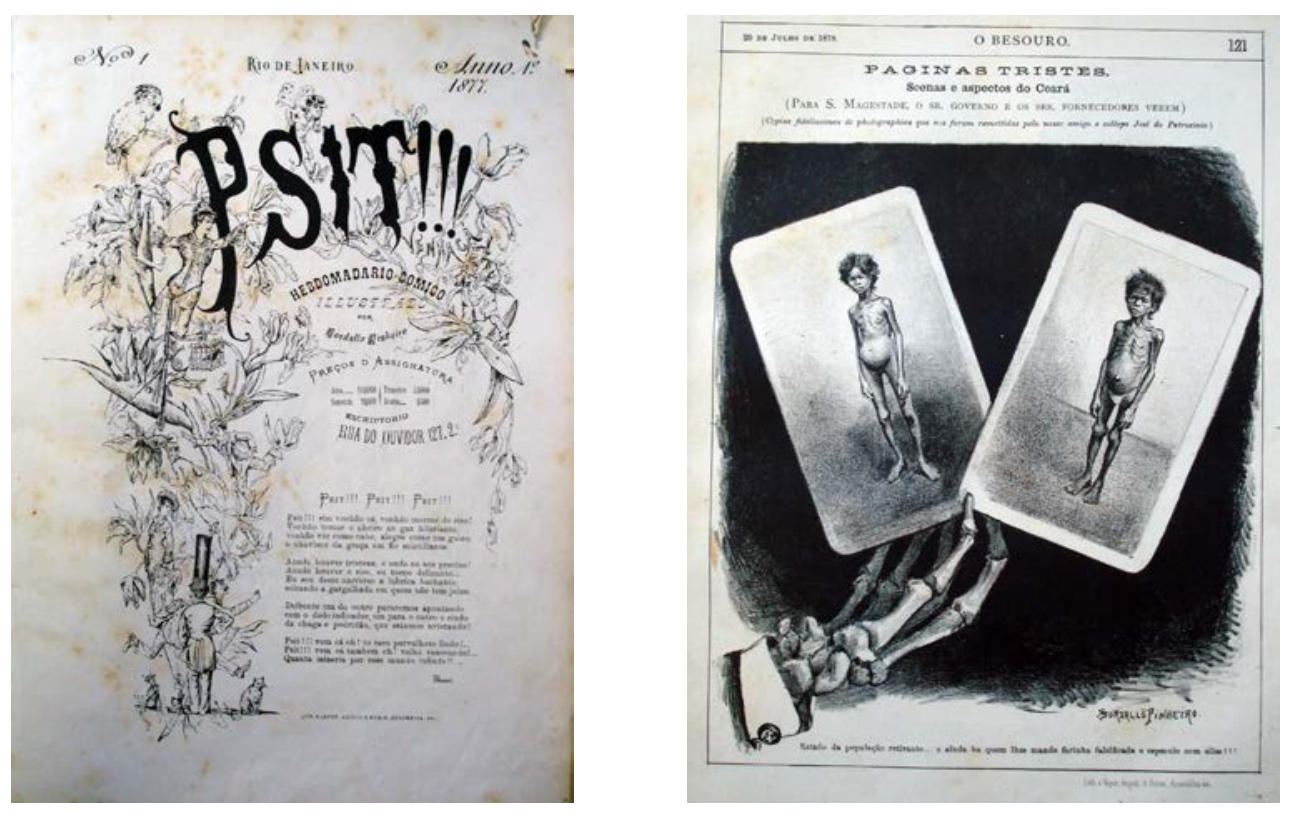

Figura 5. Capa da Psit!!!, 1877. Revista produzida por Rafael Bordalo Pinheiro.

Fonte: Psit!!!, ano 1, n. 1, 15/09/1877, capa. Acervo da Fundação Casa de Rui Barbosa.

Figura 6. O Besouro, 1878. Primeira fotorreportagem da história da imprensa brasileira. Revista produzida por Rafael Bordalo Pinheiro.

Fonte: Figura 10 - O Besouro, 20 de julho de 1878. Acervo da Fundação Biblioteca Nacional - Brasil.

Segundo Cardoso, ocorreu uma adoção generalizada de modelo e formato similares, que tornou as revistas ilustradas do Segundo Reinado muito parecidas. Para quem as enxerga com olhar apressado, é compreensível que se confundam umas com outras, pois as soluções de paginação se repetem e, em alguns casos, até mesmo os títulos são muito próximos. Para um olhar mais detido, porém, preponderam as diferenças de estilo e traço que demarcam os esforços de cada autor. Para o bem ou para o mal, as revistas ilustradas do período são extremamente autorais, e não é à toa que a tradição historiográfica costuma associar o título de uma revista ao nome do seu autor (Cardoso in Knauss, 2011, p. 28).

As cinzentas páginas de imagens realistas foram recorrentes nas produções do período. Além disso, o modo de produção e as limitações do parque gráfico determinaram formato e setorização de conteúdo nas revistas ilustradas. As revistas publicadas no Brasil no século XIX eram, em sua maioria, apresentadas em 8 páginas, sendo metade da edição dedicada à publicação das imagens litografadas e a outra metade destinada à impressão tipográfica de textos e eventualmente clichês. Existiram casos em que ocorreram exceções, como no caso da Vida Fluminense, de Agostini, que publicou edições compostas por 12 páginas, por exemplo. E as capas avulsas da revista O Besouro, que não eram computadas na sequência da paginação contínua. 
A maioria das revistas ilustradas era impressa em apenas uma cor, o preto, e a divisão de texto e imagem era clara, poucas vezes rompida por experimentações nesse sentido. A forma de produção, o custo e o tempo de execução limitavam essas experiências. Porém, apesar dos obstáculos, a impressão em cores foi experimentada em algumas revistas ilustradas, como Bazar Volante, que publicou charges coloridas em sua capa em 1863, no primeiro ano de circulação. Segundo Cardoso, possivelmente, foi pioneira ao aderir o recurso de forma recorrente. E várias outras revistas ilustradas seguiram esse exemplo nas décadas de 1860 e 1870, apesar de serem sempre experiências de curta duração (Cardoso in Knauss, 2011, p. 31-35; Teixeira, 2001, p. 14).

Com os avanços da cromolitografia, fazia-se viável imprimir uma imagem ou uma página com a aplicação limitada de cor. Mesmo assim, o processo continuava difícil e caro. As experiências nesse sentido foram logo abandonadas pela maioria das revistas que se aventuraram a realizá-las (Cardoso, 2009, p. 118).

O processo era rudimentar de tal forma que, em alguns casos, a aplicação de cores nas páginas era feita manualmente, em tiragens consideráveis. As revistas $B a-$ ta-clan, Semana Ilustrada, O Arlequim, Vida Fluminense, O Mosquito e Psit!!! também experimentaram a impressão de cores em suas páginas (Cardoso, 2009, p. 118; Cardoso in Knauss, 2011, p. 31-35).

\section{CONCLUSÃO}

As revistas ilustradas e os jornais diários no século XIX foram palco de muitas experimentações e importantes veículos de consolidação da então recente imprensa brasileira. Para Martins, havia uma diferença de funções e posicionamento que deixava clara a configuração do jornal e da revista. Enquanto o jornal focava na matéria política, as revistas publicavam sobre literatura, modas e entretenimento. Contudo isso variava, como se pode notar no forte caráter político da produção de Agostini na Revista llustrada, porém as revistas cooptavam leitores investindo na comunicação visual. Além disso, suas imagens muitas vezes se relacionavam a grupos institucionais e sociais que buscavam sua representação. Essas características fizeram toda a diferença na configuração das revistas oitocentistas brasileiras e assim permaneceram, mesmo após a implantação da imprensa industrial no século XX (Martins, 2008, p. 126-127).

Segundo Teixeira, na Monarquia as charges mantiveram características estruturais de linguagem que as singularizavam, se comparadas às charges do período republicano, "como pluralidade de quadros, abundância de textos e engajamento político" (Teixeira, 2001, p. 11). No final do século XIX, com o advento da República, foi proclamada também uma atitude de idolatria ao progresso, como forma de negação ao provincianismo pautado no modelo da sociedade escravista. A ânsia por cosmopolitismo, acentuada na Belle Époque brasileira, se disseminou pelo país, num desejo de modernização e europeização (Saliba, 2002, p. 66-70).

Tal atitude ansiosa de cosmopolitismo, já existente no período imperial, porque inspirada nos modelos de sociabilidades europeias, exerce seu domínio sobre a imaginação da sociedade brasileira e desdobra, na República, superficialmente, naquela sofreguidão de "máquinas, invenções, ingresias, francesias, ianquices que acelerassem entre eles o ritmo do progresso: industrial, técnico, mecânico e também, por coerência, político e social (Sevcenko, 1998, p. 292). 
Nesse momento de reorganização política e social, o Rio de Janeiro possuía uma população seis vezes maior que em 1808, quando a família real se mudou para o país. O crescimento urbano foi acompanhado de um aumento no consumo de bens de todos os tipos, inclusive os impressos. O design teve seu papel na reconfiguração da vida social, projetando a comunicação visual moderna através de cartazes, revistas ilustradas, embalagens e catálogos, que apresentavam e vendiam os novos produtos disponíveis no mercado (Cardoso, 2008, p. 73).

Teixeira afirma que é clara a relação entre as ditaduras militares do início do período republicano com a extinção de tradicionais revistas ilustradas. Estas haviam sido instrumentos da crítica política que proliferou durante o período anterior, eram especialmente engajadas com os questionamentos em relação à Monarquia e a abolição da escravatura. A Revista Ilustrada mudou de postura e demonstrou um adesismo estéril, e $O$ Mequetrefe desapareceu durante a ditadura de Floriano Peixoto. A partir de 1894, os governos civis de Prudente de Morais e Campos Sales viabilizaram o retorno da postura crítica das publicações e a progressiva volta das revistas ilustradas com seus traços de sátira e humor.

As revistas ilustradas traduziam em suas páginas o sentimento moderno e a busca do progresso pela sociedade. Elas mediavam a assimilação pela população das mudanças instauradas nas cidades e na vida privada. O humor estava sempre presente nas representações e sátiras e, embora não tivesse nascido com a República, adquiriu novas dimensões e abrangência com o crescimento urbano do país e com o significativo incremento da imprensa nesse período, haja vista o aperfeiçoamento tecnológico das oficinas gráficas (Sevcenko, 1998, p. 297-298; Saliba, 2002, p. 39). Esses avanços gráficos permitiram que as revistas semanais se destacassem pelo seu grande potencial comunicativo amparado pela visualidade. (Velloso in Oliveira, 2010, p. 89; Sussekind, 1987, p. 36; Teixeira, 2001, p. 12).

O autor Daniel Roche, em seu livro O Povo de Paris: ensaio sobre a cultura popular no século XVIII, afirma que a literatura teve papel importante para as mudanças do povo parisiense. Salienta a aplicação dos leitores que tinham que vencer barreiras como custo, más condições de moradia, iluminação, e dificuldades de decifrar caracteres mal impressos. A superação possibilitou a evolução da literatura difundida por vendedores ambulantes, a proliferação de títulos, o enriquecimento dos temas, abrindo caminho para outras leituras e permitindo a apropriação de diferentes saberes. A partir disso, o autor afirma que a cultura do povo tem suas fontes e que é preciso entender as maneiras de ler urbanas (Roche, 2004, p. 299). Podemos associar essas informações à proliferação de títulos e ao sucesso das revistas ilustradas brasileiras no final do século XIX, que eram o lugar da democratização da literatura e do humor no país. Sem ainda poder falar em uma expressiva distribuição e disseminação de livros no Brasil nesse período, pode-se ponderar o papel das revistas na integração da cultura das ruas e sua gama de valores, percepções, práticas e personagens. Nesse final de século, era latente o confronto entre o moderno e o arcaico, entre a "cultura livresca" e a "cultura das ruas", que integravam grupos até então à margem da vida social. A revista se destacava também como uma alternativa de leitura no trânsito das pessoas nos centros urbanos e seus novos meios de transporte, já que ler um grande livro não era prático e a leitura tinha que ser interrompida diversas vezes. Com artigos de diferentes tamanhos, publicação de 
imagens e o tom ditado pelo humor, as revistas ganharam seu lugar no tempo acelerado e no dinamismo da modernidade (Velloso in Oliveira, 2010, p. 57).

Embora se saiba que a história da imprensa ilustrada brasileira conta com numerosos títulos e produtores, neste artigo são apresentadas informações de forma abrangente. Sabe-se que para o aprofundamento acerca dos títulos que foram publicados na segunda metade do século XIX serão necessárias pesquisas sobre cada uma das revistas e seus produtores. Essas investigações são importantes para os estudos da memória gráfica brasileira e contribuem para a construção da história do design no Brasil.

\section{REFERÊNCIAS}

BAUDELAIRE, Charles. 0 pintor da vida moderna. Concepção e organização Jérôme Dufilho e Tomaz Tadeu. Belo Horizonte: Autêntica Editora, 2010.

CARDOSO, Rafael (Org). Impresso no Brasil, 1808-1930: destaques da história gráfica no acervo da Biblioteca Nacional. Rio de Janeiro: Verso Brasil, 2009.

(Org.). 0 design brasileiro antes do design: aspectos da história gráfica, 18701960. São Paulo: Cosac Naify, 2005.

. Uma introdução à história do design. 3. ed. rev. e ampliada. São Paulo: Editora Edgard Blücher, 2008.

FERREIRA, Orlando da Costa. Imagem e letra. Introdução à bibliologia brasileira: a imagem gravada. São Paulo: Editora da Universidade de São Paulo, 1994.

KNAUSS, Paulo et al. (organizadores). Revistas llustradas: modos de ler e ver no Segundo Reinado. Rio de Janeiro: Mauad X: FAPERJ, 2011.

MARTINS, Ana Luiza. Revistas em revista. Imprensa e práticas culturais em tempos de República (1890-1922). São Paulo: Editora da Universidade de São Paulo, Fapesp: Imprensa Oficial do Estado, 2008.

NERY, Laura Moutinho. A caricatura: microcosmo da questão da arte na modernidade. 2006. 233 f. Tese (Doutorado) - Departamento de História, Pontifícia Universidade Católica do Rio de Janeiro, Rio de Janeiro, 2006.

; Henrique Fleuiss e sua Semana Ilustrada. Revista Educação em Linha. p. 64-66, 2011.

OLIVEIRA, Claúdia de; VELLOSO, Monica P.; LINS, Vera. O moderno em revistas: representações do Rio de Janeiro de 1890 a 1930. Rio de Janeiro: Garamond, 2010.

ROCHE, Daniel. O povo de Paris: ensaio sobre a cultura popular no século XVIII. São Paulo: Edusp, 2004.

SALIBA, Elias Thomé. Raízes do riso - a representação humorística na história brasileira: da Belle Époque aos primeiros tempos do rádio. São Paulo: Companhia das Letras, 2002.

SEVCENKO, Nicolau (org.). História da vida privada no Brasil. República: da Belle Époque à Era do Rádio. São Paulo: Companhia das Letras, 1998.

SODRÉ, Nelson Wernek. História da Imprensa no Brasil. 4. ed. Rio de Janeiro: Mauad, 1999. 
SÜSSEKIND, Flora. Cinematógrafo de letras: literatura, técnica e modernização no Brasil. São Paulo: Companhia das Letras, 1987.

TEIXEIRA, Luiz Guilherme Sodré. 0 traço como texto: história da charge no Rio de Janeiro de 1860 a 1930. Rio de Janeiro: FCRB, Cadernos Avulsos, no 38, 2001.

VELLOSO, Mônica Pimenta. Modernismo no Rio de Janeiro: turunas e quixotes. Rio de Janeiro: Editora Fundação Getulio Vargas, 1996. 